The Benefits of Autonomy Support for Adolescents

with Severe Emotional and Behavioral Problems

Audrey Savard, Mireille Joussemet, Julie Emond Pelletier, and Geneviève A. Mageau

Université de Montréal

To cite this article: Savard, A., Joussemet, M., Emond Pelletier, J., \& Mageau, G. A. (2013). The benefits of autonomy support for adolescents with severe emotional and behavioral problems. Motivation and Emotion, 37(4), 688-700. doi:10.1007/s11031-013-9351-8

To link to this article: https://link.springer.com/article/10.1007/s11031-013-9351-8

Author Note

Audrey Savard, department of psychology, Université de Montréal; Mireille Joussemet, department of psychology, Université de Montréal; Julie Emond Pelletier, department of psychology, Université de Montréal, Geneviève A. Mageau, department of psychology, Université de Montréal.

This research was supported in part by grants from the Fonds Québécois de Recherche sur la Société et la Culture (FQRSC) and the Social Sciences and Humanities Research Council of Canada (SSHRC). We thank the Centre Jeunesse de Montréal - Institut Universitaire - for their partnership in the project.

Correspondence concerning this article should be addressed to Mireille Joussemet, department of psychology, Université de Montréal, Québec, Canada. E-mail: $\underline{\text { m.joussemet@umontreal.ca }}$ 


\begin{abstract}
AUTONOMY SUPPORT FOR ADOLESCENTS WITH PROBLEMS
Abstract

The benefits of autonomy support in the domain of education have been well established within the general population, but have yet to be demonstrated within clinical populations. The present study investigated the benefits of an autonomy-supportive interpersonal style on teenage girls' internalization of a tedious clinical workshop and their subjective experience during this task. Participants were female teenagers placed in a social rehabilitation center for their severe emotional and behavioral problems $(n=29)$. An experimental design allowed comparing the impact of learning a tedious, but important workshop with or without autonomy support on internalization and experiential outcomes. Results demonstrate that autonomy support leads to higher perceived task's value, task liking as well as less negative affect compared to a condition without autonomy-support. Participants in the autonomy-supportive condition also perceived the instructor as more competent. By uncovering benefits of autonomy support to a clinical population of adolescents, the present study supports self-determination theory's tenet that the benefits of autonomy support are universal.
\end{abstract}

Keywords: Autonomy support, internalization, well-being, motivation, clinical population 


\title{
The Benefits of Autonomy Support for Adolescents with Severe Emotional and Behavioral Problems
}

\begin{abstract}
After facing several contextual and developmental challenges, children and adolescents placed in social rehabilitation centers (SRCs) who show severe psychosocial difficulties are at especially high risk for later mental health problems. Social Rehabilitation Centers (SRCs) are residential placement settings in the province of Quebec (Canada), ${ }^{1}$ aiming to protect youngsters from their milieu and to offer treatment for psychosocial problems, both internalized and externalized. SRCs provide residential setting services during which socialization is mainly assumed by educators and prompted with clinical workshops to improve social skills such as communication and problem solving. Because educators are becoming these youths' primary socialization agents, the interpersonal style they use may be an important factor in providing an optimal social rehabilitation environment.
\end{abstract}

Within SRCs, clinical workshops are offered to foster youths' social skills and eventually, their social rehabilitation. Unfortunately, youths' motivation and internalization of such skills is lacking. Indeed, the few studies following teenagers who had received SRCs services report persistent problems and recurrent need of social services (Toupin, Pauzé, \& Déry, 2005), suggesting that the new skills have not been internalized. For example, $67 \%$ of adolescents who receive services in Quebec SRCs have already received social services and 61\% have already been placed in SRCs in the past (Thibault, 2005). Besides, many youngsters who leave SRCs still present social, emotional and behavioral problems when re-evaluated later in life (Lanctôt, 2006; Thibault, 2005). For instance, many are poorly educated, live in precarious socio-economical conditions, and/or with violent partners. There are also high rates of delinquency, substance abuse and mental health problems among those youths. 
Perhaps because of the manifested behavioral and emotional problems, socializing agents (i.e., responsible adults such as parents, educators and teachers) who interact with difficult youngsters tend to use controlling strategies (Anderson, Lytton, \& Romney, 1986; Grolnick \& Apostoleris, 2002; Jelsma, 1982). Not only do difficult youths "pull for control” (Grolnick, 2003) by eliciting strong emotional reactions, but it is often believed that authoritarian interpersonal styles and controlling strategies are the only means to foster difficult youths' motivation and cooperation (e.g., external contingencies; see Witzel \& Mercer, 2003, for a review). In contrast to this common practice and belief in controlling interpersonal styles, which might be influenced by several reasons (see Reeve, 2009, for a review), a wealth of research demonstrates that paradoxically, controlling practices impair youths' motivation and internalization. Furthermore, such strategies were also found to increase the likelihood of psychosocial problems among youngsters (Barber, 1996; Grolnick \& Apostoleris, 2002; Ryan \& Deci, 2000; Soenens, 2006).

A fundamental goal of socialization is the internalization of socially accepted rules, behaviors and values. Internalization is the process by which individuals can actively change external requests from the socialization context into personally endorsed values and autonomous behaviours (Grusec, Goodnow, \& Kuczynski, 2000; Grusec \& Kuczynski, 1997; Ryan, 1995). Within the Self-Determination Theory perspective (SDT; Deci \& Ryan, 1980, 1985, 1991, 2000; Ryan \& Deci, 2000), internalization is said to be a natural and universal tendency. In other words, individuals are viewed as active organisms that naturally tend to "take in" social values, in order to gain or maintain well-being and self-development. Although natural, the essential need for autonomy (along with relatedness and competence) has to be fulfilled for this process to 
take place. Internalization thus depends on social contexts, which can either nurture or thwart the need for autonomy (see Ryan, Deci, Grolnick, \& La Guardia, 2006, for a review).

Autonomy refers to the experience of initiating and/or regulating behaviors from one's sense of self, with a sense of volition, as opposed to feeling controlled (De Charms, 1968; Ryan et al., 2006). According to SDT, the need for autonomy is inherent to all human beings, without exception (e.g., age, culture, or socio-demographic background). If the need for autonomy is universal, maladjusted teenagers should also benefit from autonomy-supportive contexts.

In contrast to pleasurable, intrinsically motivating activities, extrinsic motivation pertains to important tasks that may be perceived as uninteresting and need to be externally prompted. The subjective experience during the internalization of such tasks varies greatly. The degree to which individuals see the task's importance differs, as well as the level of unpleasant emotions (e.g., frustration, anxiety) they experience. According to SDT, the success of the internalization process varies as a function of the extent to which the regulation feels self-determined (Vansteenkiste, Niemiec, \& Soenens, 2010).

To foster internalization, it has been proposed that socializing agents should provide autonomy support. The concept of autonomy support was first operationalized as offering choice, rationale, and empathy (Koestner, Ryan, Bernieri, \& Holt, 1984). This definition was based on Ginott's (1959) writings on impersonal and empathic limit setting, which also inspired a parenting program teaching autonomy-supportive communication and strategies (e.g., impersonal feedback and expectations; Faber \& Mazlish, 1980). Autonomy support should not be confused with permissiveness, the opposite of behavioural control (or structure; i.e. clear and consistent guidelines, expectations and consequences; Nie \& Lau, 2009). The opposite of 
autonomy support is psychological control; controlling practices that constrain, invalidate and manipulate others (Barber, 1996). While psychological control is associated with negative developmental and psychological outcomes (e.g., Grolnick \& Apostoleris, 2002; Soenens, 2006), structure is associated with positive motivational outcomes and has a complementary role with autonomy support (Connell \& Wellborn, 1991; Grolnick, 2003; Jang, Reeve, \& Deci, 2010; Sierens, Vansteenkiste, Goossens, Soenens, \& Dochy, 2009).

Empirical studies across various life domains (e.g., education, sports, health) have shown that when individuals perceive their socializing agents to be autonomy-supportive, they experience a vast range of positive experiential outcomes (see Ryan \& Deci, 2000, for a review). In the education domain, associated benefits found within normative student populations of adults, adolescents and children include increased well-being (Black \& Deci, 2000; Deci \& Ryan, 2000; La Guardia \& Ryan, 2002; Ryan \& Deci, 2000), persistence (Hardre \& Reeve, 2003; Vallerand \& Bissonnette, 1992; Vallerand, Fortier, \& Guay, 1997), engagement, interest, value (Jang, 2008; Reeve, Jang, Carrell, Jeon, \& Barch, 2004; Tsai, Kunter, Ludtke, Trautwein, \& Ryan, 2008), and competence (Black \& Deci, 2000; Deci \& Ryan, 2002; Jang, 2008).

Importantly, a number of experimental studies have repeatedly shown that autonomy support promotes the internalization of the tasks taught by socializing agents. Conducted within the general population, the following experiments have looked at the direct impact of autonomy support (vs. controlling or neutral contexts) in an extrinsic motivation context (i.e., when limits are set or uninteresting tasks are prompted).

First, in a study with young children, Koestner et al. (1984) manipulated the manner in which limits were set during a painting activity (neatness). Results revealed that intrinsic 
motivation, enjoyment, creativity and quality of arts were greater when limits were set with an autonomy-supportive style, compared to the condition with controlling limits (shoulds and musts). This study suggests that autonomy support can promote healthy motivation, pleasure and performance, even in a context of external constraints.

In an experiment with young adults, Deci, Eghrari, Patrick, and Leone (1994) tested whether the autonomy-supportive elements of choice, empathy and rationale (Koestner et al., 1984) fostered more self-determined forms of motivation for an uninteresting activity. Results revealed that directives including a higher number of autonomy-supportive elements led to higher self-determined self-regulation, measured by congruency between feelings toward the task and later decisions to freely engage in it.

Furthermore, three studies with college students (Jang, 2008; Reeve, Jang, Hardre, \& Omura, 2002) demonstrated that during uninteresting activities, providing a rationale in an autonomy-supportive way promotes higher self-determined motivation as well as subsequent task effort in the task, compared to a context without rationale and autonomy-supportive communication.

Finally, Joussemet, Koestner, Lekes, and Houlfort (2004) conducted two experiments with regular school children to compare the effects of autonomy support and rewards on children's motivation to engage in a tedious task. Results revealed that autonomy support promoted more positive affect, perceived task's value, and self-determined regulation compared to rewards. Interestingly, the benefits of autonomy support were not moderated by students' selfregulatory capacity, as assessed by teachers, suggesting that autonomy support was beneficial even for more difficult children. 
This idea that the benefits of autonomy-supportive contexts can also be present for more challenging students has also been supported in two recent studies (Black \& Deci, 2000; Reeve et al., 2004). In both experiments, a training was found to increase instructors' autonomy support which, in turn, led to an improvement in students' well-being, self-determination, performance and engagement, even when students' initial motivation toward the task was poor (Black \& Deci, 2000), and in spite of prior engagement (Reeve et al., 2004). Thus, although youths' characteristics do influence the level of autonomy support used by their socializing agents, the motivational and learning benefits of autonomy support do not seem to be limited to welladjusted students.

These studies provide strong empirical support to the idea that autonomy-supportive contexts facilitate individuals' autonomous motivation and well-being. It appears that autonomy support tends to be associated with higher internalization and more self-determined regulation than controlling educational practices. The experimental studies suggest that the positive impact of autonomy support holds true even when a task is not interesting and when participants show a wide range of motivation/regulation.

Unfortunately, children and adolescents in social rehabilitation centers (SRCs) seem to identify poorly with the social values underlying the skills taught within social rehabilitation workshops. When youths do not perceive that these skills are congruent with their own values or feelings, their sense of volition and responsibility is low, hindering the internalization process. If the main goal socializing agents have for youth is a healthy and long-term internalization of skills rather than mere situational obedience, it seems that an autonomy-supportive interpersonal style should be favoured within learning environments (Deci \& Ryan, 2000). 
To our knowledge, no study has investigated the benefits of autonomy support among a population of severely impaired youngsters. The present study aims at extending previous findings to a population of teenage girls with severe emotional and behavioral problems. Considering that in previous studies (Black \& Deci, 2000; Joussemet et al., 2004; Reeve et al., 2004), autonomy support was beneficial for a heterogeneous group of students (e.g., various levels of initial motivation, engagement and self-regulation), it seems important to verify whether the seemingly universal positive effects of autonomy support will extend and hold true within a clinical population of teenage girls. In other words, do adolescents with severe emotional and behavioral difficulties also profit from autonomy support? The goal of the present experiment, conducted with teenage girls placed in SRCs, was to measure the impact of an autonomy-supportive (AS) interpersonal style (vs. without autonomy support, NoAS) on the internalization of a tedious task. It was hypothesised that an AS context would be predictive of a better subjective experience (i.e., subjective well-being and autonomy), a better internalization and appreciation of the task (i.e., task value and task liking,) and appraisal of the instructor (i.e., perception of her competence).

\section{Method}

\section{Participants}

Participants were 29 French-speaking female adolescents between 13 and 17 years old $(M=14.5$ years old; $S D=1.2$ year $)$, placed in a youth SRC in the Montreal area for their severe emotional and behavioral difficulties. It is important to highlight that SRCs are residential facilities dedicated to those who are too severely impaired behaviourally and/or emotionally to receive services or placements within the community. When placed in a SRC, youngsters have 
often grown up into the adversity of neglect and/or abuse and are now suffering from important social, behavioral and emotional maladjustment. Within our sample, teenage girls had received social services for an average of 3 years (ranging from 1 month to 13 years; $M=36.76$ months; $S D=43.42$ months). This information illustrates the severity of their maladjustment and the need for long term rehabilitation services in many. Boys were not included in the sample since SRCs are gender specific (difficulties, needs and services offered may vary largely across placements settings; e.g., young offenders units are available in boys SRCs only).

After having received the approval from the ethic committee, parental or legal guardian consents were obtained by phone, before soliciting adolescents. Next, girls for whom parental consent was obtained were recruited. They were told that the participation consisted of completing an initial questionnaire assessing how they usually feel during clinical workshops in SRCs (i.e., baseline autonomy) and, during a subsequent visit, engaging in a one-hour clinical workshop on interpersonal problem solving, followed by a questionnaire. The compensation offered was a chance $(\geq 1 / 6)$ to win a bookstore gift certificate of $20 \$$. Eight experimental groups (n from 2 to 6) were formed randomly, within 5 living units (comprising up to 12 teenagers living together) to ensure all participants in a group would know each other. Groups were then randomly assigned to one of the two conditions: with or without autonomy support (AS, $\mathrm{n}=17$; NoAS, $\mathrm{n}=12)^{2}$

\section{Experimental Task}

The experimental task was a clinical workshop, teaching the necessary steps of interpersonal problem solving. It is considered as a potentially uninteresting activity that is important to internalize for teenagers placed in SRCs. Although problem solving might be 
interesting, this activity was chosen based on the clinical experiences of a "development agent" working at SRCs, who attests that some clinical activities are more interesting to teenage girls than others, and that this one is not much appreciated because of its tedious format requiring learning a "recipe" (S. Fagnan, personal communication, August $\left.3^{\text {rd }}, 2009\right)$. The experimental task was inspired from a workshop already used in other SRCs (S. Fagnan, personal communication, August $3^{\text {rd }}, 2009$ ) and designed by Schultz, Selman, and Yeates (1989). The working material was chosen to avoid stimulating girls' interest with specific topics. Thus, this clinical workshop is ecologically valid, represents a monotonous task and corresponds to the kind of social rehabilitation workshops that teenage girls have to attend to, when placed in SRCs.

\section{Procedure}

Clinical workshop. Two experimenters were present during the workshop. The first was presented as a workshop instructor from the University of Montreal who is interested in offering and evaluating this particular activity. The second experimenter was introduced as a workshop evaluator.

After introducing herself, the instructor distributed name tags and workbooks, with written information that matched the group's experimental condition. Before beginning the activity, the instructor presented its learning objectives (to define the problem, generate various solutions, oversee their consequences) and stated her expectations (i.e. listening to explanations, asking questions, raising hands before talking, etc.) A first interpersonal problem was then introduced:

\footnotetext{
"Luc goes to his best friend Jérôme's place. When he arrives, he finds on the bed the latest IPod he will never be able to get because of its price. Luc is
} 
dying to have it. Thus, he takes Jérôme's IPod and hides it in his bag without a second thought. When Jérôme comes back into his bedroom, he does not see right away that his IPod has disappeared, but when Luc leaves, he realises that his IPod is no longer there. Jérôme knows that Luc took his IPod.”

First, the steps required to solve problems were presented and the group solved the problem together for about 40 minutes. The group identified the problem and brainstormed about why the situation was problematic, and what were the possible emotions Jérôme felt. Then, Jérôme's potential solutions to deal with the situation were identified by the group and advantages/disadvantages were thought through. The best solution was thereafter chosen by the group, keeping in mind the underlying expectations of how each boy would possibly feel with that solution. As a final step, the group predicted the possible consequences of the solution to make sure it would be fair to both boys.

After having learned the steps and solving a problem in group, participants were presented a second interpersonal problem and asked to solve it individually, using their workbook. The same problem solving steps were involved. Individual work lasted 10 minutes, as the instructor answered questions and gave positive individual feedback to all.

Experimental manipulation. Experimental conditions were created by manipulating the instructor's instructions and interpersonal style. Girls in both conditions attended to the same clinical workshop which was presented either in an autonomy-supportive (AS) or a non autonomy-supportive (NoAS) way. The instructor learned scripts prepared for each type of instructions to minimize differences in other interpersonal aspects that could influence participants (e.g., level of enthusiasm, irritability; see below). In addition, the instructor was 
trained to interact in one or the other style spontaneously, by learning responses and reactions corresponding to each experimental condition. These efforts were made to ensure that interactions would be coherent with the experimental context, throughout the workshop, within each condition. Experimental manipulation accuracy was verified by the second experimenter, who observed the activity, followed the script to insure fidelity, and categorized each additional, spontaneous interventions used as autonomy-supportive or not (i.e., "typical"), to insure coherence within each condition.

The AS condition was based on the operational definition of autonomy support: providing rationale, choice and empathy (Koestner et al., 1984). The wording of instructions was adapted from previous studies (Deci et al., 1994; Joussemet et al., 2004). For example, after presenting the dilemma to the group, the instructor conveyed rationale and empathy:

"Before we start girls, I would like to tell you the reason why we will practice together with an imaginary story today. It's because it might be easier to solve an imaginary problem than a real life problem, like a fight for example. Even then, it is not necessarily easy to solve a pretend problem, because it is new and it might seem like a lot of steps to learn! So, first we will practice with fake problems and then, the more we practice, the more it might become easier and more natural for you to do. Later on, when you will be facing a real fight that you want to solve, this is likely to help you."

Rationale and empathy were also offered when it was time to work individually. During that second part of the workshop, choice was provided by allowing girls to choose how to 
proceed: "This answer sheet contains the same questions (steps) as in the first dilemma; you can do it in the order that is the most helpful to you".

As to setting limits when needed during the activity, impersonal limit statements (Koestner et al., 1984) and other non-controlling communication skills (Faber \& Mazlish, 1980; Ginott, 1965) were used. For instance, when setting limits about talking during an inappropriate moment, the instructor stated her expectations in an impersonal way (e.g., "This part of the workshop requires to be done in silence"). When inappropriate behaviours needed to be ended, the instructor could use non-controlling communication skills such as empathy: "It might be very difficult to remain silent when sitting beside a friend"; choice: "If it is too difficult you can choose to sit elsewhere"; and actions: "I see you chose to sit elsewhere".

Finally, the positive feedback instructor gave during the individual part of the activity was descriptive rather than evaluative (Faber \& Mazlish, 1980; Ryan, 1982). This type of feedback prevents evaluative pressure. It included either a description of what had been accomplished or of what remained to be done (E.g., "I see you found 3 solutions!; There was a lot of thinking done here, only one step left and it's completed").

In contrast, groups in the NoAS condition did not receive any of the autonomy-supportive elements of rationale, empathy or choice during instructions. As in other studies (e.g., Edmunds, Ntoumanis, \& Duda, 2008; Sheldon \& Filak, 2008), the purpose of this non autonomysupportive condition was to obtain, as much as possible, a "neutral" or typical condition, that would imitate the interpersonal style commonly used within clinical workshops given by SRCs' educators. Contrary to other experiments creating controlling conditions to make participants feel pressured (e.g., Sheldon \& Filak, 2008), no controlling strategies were added because this 
condition did not attempt to undermine the participants' subjective experience of autonomy.

Neither was the absence of autonomy-supportive elements in the NoAS condition made salient. However, since requests had to be made in the present study, limits were set and behavioral control was obtained, by using traditional language such as "you have to..." and sentences beginning with verbs. The positive feedback provided was evaluative in nature, reproducing praise typically offered (e.g., "Wow, you did an excellent job!"; see Table 1 for a comprehensive comparison between autonomy-supportive and "typical" statements). ${ }^{3}$

\section{Self-reports and Debriefing}

Thereafter, two research assistants that had been waiting outside of the room came in to hand out questionnaires. One of them read it out loud along with participants, to avoid misunderstanding due to reading problems, a common problem among this population. The second assistant was there to answer individual questions. The assistants reminded participants that questionnaires allow them to express what they thought of the activity and how they felt while doing it. The scales were adapted for uniformity, with all likert scale items ranging from 1 “do not agree at all" to 7 "very strongly agree". A week later, experimenters met with each participant individually to give descriptive positive feedback and debrief them about the exact purpose of the project (i.e., to assess motivation and appraisal of the task) and the presence of two ways in which it was offered. The understanding of participants and the impact of this information on them was evaluated carefully and discussed unhurriedly.

\section{Measures}

Manipulation check. In addition to AS interventions made from the script, the instructor's interpersonal style during non-scripted, spontaneous utterances were quantified and 
categorized as autonomy-supportive or "typical" by the second experimenter (see "Limit setting" and "Taking action" in Table 1). In addition, the level of enthusiasm (one item) and irritability (one item) in the voice and facial expression of the instructor was assessed for each group, on a scale from 1 (low) to 6 (high). These measures were used to verify whether, as expected, the experimental conditions differed on the number of autonomy-supportive and "typical" comments. In contrast, conditions were not expected to differ on the level of enthusiasm and irritability displayed.

Subjective well-being and autonomy. In order to assess positive and negative affect among a population of teenage girls with possible reading/academic and emotional difficulties, we created a new French scale. Indeed, a pilot study with our population using an adapted French version of the 20-item positive and negative affect scales (PANAS; Watson, 1988; Laurent et al., 1999) revealed that the vocabulary was difficult to understand for severely impaired adolescents. Consequently, the psychometric structure differed from previous validation studies (Huebner \& Dew, 1995; Huebner \& Dew, 1996). Taking the academic difficulties of this population into account, a new scale was constructed using the PANAS (Watson, Clark, \& Tellegen, 1988) and the PANAS for children (Laurent et al., 1999) as models. The scale includes 10 positive (e.g., "Happy"; $\alpha=.93$ ) and 10 negative (e.g., "Sad"; $\alpha=.90)$ emotion items. The instructions targeted how participants felt during the workshop, using simple vocabulary (items can be found in the Appendix).

Items of already existing scales were adapted to measure how much adolescents felt autonomous during the workshop. A total of 9 items were used to measure feelings of Autonomy $(\alpha=.87$; Blais \& Vallerand, 1991; Forest \& Mageau, 2008; La Guardia, Ryan, Couchman, \& Deci, 2000; Sheldon \& Filak, 2008). Items were adapted in order to reflect the situational context 
of the experiment as well as girls' perceived need satisfaction rather than their perception of the instructor's autonomy support (e.g., "During the activity, I felt I had choices about how to apply the learned skills" rather than "The instructor offered me choices about how to apply the learned skills"). While already existing scales tend to use both types of items, our goal was to measure girls' sense of autonomy. Hence, this measure does not represent a manipulation check of how the instructor behaved, but the inner feelings of teenagers' perceived autonomy during the workshop (items can be found in the Appendix).

Task value and task liking. To assess task internalization, teenage girls' perceived value of the workshop was also estimated, with five items $(\alpha=.86)$ translated and adapted from previous studies (Boggiano, Flink, Shields, Seelbach, \& Barrett, 1993; Tsai et al., 2008). Participants' perceived liking of the workshop was estimated with four items $(\alpha=.91)$ translated and adapted from previous studies (e.g., "I appreciated solving dilemma"; Boggiano et al., 1993; Tsai et al., 2008).

Perceived instructor's competence. Finally, girls also evaluated the instructor's competence (Boggiano et al., 1993), using two items: "I consider that the instructor was efficacious to teach me to solve problems" and "I consider that the tips and strategies of the instructor were useful to me" $(\alpha=.84)$.

Individual differences. Information was collected in order to control for individual differences if needed. Teenage girls answered questions about their origin, age, academic level and grades (mathematics and French) and the length of their own use of social services. Girls' SRC educators were also asked to provide information about teenagers' self-regulatory capacity, using a computed score of items from an adapted version of the Conners' Teacher Rating Scales 
assessing opposition, anxiety, emotional lability and aggressiveness (15 items, $\alpha=.79$; Conners, 2000).

Because clinical workshops that are similar to the experimental task are commonly offered within SRCs, a baseline measure of autonomy felt during clinical workshops in general had been obtained, during the first visit. All but one item from the measure used to assess autonomy during the situational, experimental task was used ( 8 items, $\alpha=.78)$. The stem and items were adapted in order to reflect to contextual level (e.g., "In general, during clinical workshops... I feel free to express my ideas and my opinions.”)

\section{Results}

\section{Preliminary Analyses}

In order to assure that the experimental conditions had been coherent throughout the workshop and were different from each other on the key autonomy support (AS) factor, spontaneous, additional interventions (e.g., limit setting) noted/categorized by the second experimenter were computed and t-tests were performed. Results revealed significant differences in the expected directions in the mean number of spontaneous autonomy-supportive comments $(t(23.92)=10.34, p<.01)$, and of "typical" comments $(t(27)=-15.65, p<.01)$. No difference was found between groups in the level of the instructor's enthusiasm $(t(27)=1.20$, ns $)$ and irritability displayed $(t(26.58)=1.14, \mathrm{~ns})$. All means can be found in Table 2.

Preliminary analyses also investigated the possible impact of individual differences on the main dependent variables (i.e., positive and negative affect, autonomy, task value, task liking, and perceived instructor's competence). Correlational analyses examined the influence of the following factors: origin, age, academic level, grades (mathematics and French), length of use of 
social services, self-regulatory capacity and baseline feeling of autonomy. Baseline feeling of autonomy was significantly correlated with feeling of autonomy $(r=.39, p<.05)$, and value $(r=$ $.39, p<.05)$. These correlations indicate that the higher the habitual feeling of autonomy during clinical workshops, the more participants felt autonomous during the experimental task and valued it more. Aside from baseline feeling of autonomy, the only other significant correlation that emerged was between length of use of social services and perceived instructor's competence, indicating that the more teenage girls received social services, the less competent they perceived the instructor to be $(r=-.40, p<.05)$.

\section{Principal Analyses}

First, a series of t-tests with experimental condition as the independent variable were performed on each of the six dependent variables, namely: positive affect, negative affect, autonomy, task value, task liking, and perceived instructor's competence (correlations among dependent variables can be found in Table 3). Next, ANCOVAs were performed on autonomy and task value, using baseline feeling of autonomy as a covariate. An Ancova was also conducted on perceived instructor's competence, with length of use of social services as a covariate. All means can be found in Table 2.

Subjective well-being and autonomy. Well-being is an important part of a healthy learning environment and has been found to be increased by AS. We speculated that the wellbeing of difficult teenage girls would also be significantly facilitated by an AS interpersonal style. There was no discernible difference in positive affect across conditions $(t(27)=1.44$, ns).

In contrast, negative affect was significantly lower in the AS interpersonal context, $(\mathrm{t}$ $(14.72)=-2.91, p=.01, d=1.28)$, compared to participants in the NoAS condition. Thus, it 
seems the experience of learning a tedious activity was eased for difficult teenage girls by the providing them an autonomy-supportive learning environment.

It was also hypothesized that the manipulation of the interpersonal style would influence youths' feeling of autonomy. Although mean ratings were in the expected directions, the t-test did not reach significance $(t(27)=1.08$, ns). The Ancova, controlling for the habitual feeling of autonomy during SRC clinical workshop, did not yielded a significant effect either $(F(1,25)=$ $0.36, \mathrm{~ns})$.

Task value and task liking. A t-test was conducted on the perceived value of the task to assess the impact of AS on internalization. Results indicate that participants in the AS condition rated the task as more important, useful and meaningful to them, $(t(27)=3.08, p=0.01, d=$ 1.13), compared to participants in the NoAS condition. This result was also found when controlling for girls' baseline feeling of autonomy during clinical workshops in general $(F(1$, $\left.25)=8.02, p=.01, R^{2}=0.24\right)$.

In line with studies conducted with normative population, results demonstrated that task liking was also higher when teenagers attended the workshop in the AS condition, compared to the NoAS one $(t(27)=2.51, p<.05, d=0.95)$.

Perceived instructor's competence. Results from the analysis show that the perceived instructor's competence was significantly higher in the AS condition than in the NoAS condition, $(t(15.31)=2.70, p<.05, d=1.12)$. This impact is also found when controlling for girls' length of use of social services, $\left(F(1,26)=4.82, p<.05, R^{2}=.16\right)$. It seems that AS had a positive impact on the way difficult teenage girls evaluated the competence of a new socializing agent. 


\section{Supplemental Analyses}

Testing participants in groups may have created score dependency, which in turn can decrease error term estimates and increase type I error probabilities. To estimate the importance of this potential bias, we conducted HLM analyses to explore whether similar results would be obtained (despite the obvious lack of power and stability that result from using a small sample size). Hierarchical Linear Modeling (HLM) analyses consider the hierarchical structure of the data by computing a regression equation for each level-2 unit (i.e., each group), with an intercept (a mean; $\beta_{0}$ ) and, when modeled, a slope $\left(\beta_{1}\right)$ per group. From these regression equations, HLM analyses provide the grand mean of the dependent variable $\left(\gamma_{00}\right)$, which represents the averaged intercepts $\left(\beta_{0 \mathrm{j}}\right)$ of each regression equation, in addition to modeling the intergroup variability of these intercepts around the grand mean (Raudenbusch \& Bryk, 2002). To test the impact of our experimental condition on this intergroup variability, a model was tested for each outcome, where the experimental condition was entered as a level-2 predictor of the intercepts (or means). The coefficient $\gamma_{01}$ in this equation thus represents the averaged impact of the experimental condition across groups and may be interpreted as the average difference between the AS and NoAS groups. The equation for each outcome is:

$$
\text { Outcome }_{i j}=\gamma_{00}+\gamma_{01} \text { Condition }_{i j}+\left[\varepsilon_{i j}+\zeta_{0 j}\right]
$$

Results showed that the experimental condition had a significant effect for three dependent variables (i.e., negative affect, $\gamma_{01}=-1.57, p<.05$, task value, $\gamma_{01}=1.81, p<.05$, instructor's competence, $\gamma_{01}=2.03, p=.05$ ) and a marginally significant effect for the other dependent variable that was originally reported to be affected by the experimental condition (i.e., task liking, $\left.\gamma_{01}=1.94, \mathrm{~ns}\right)$. 


\section{Discussion}

The goal of the present study was to assess whether internalization and well-being benefits of autonomy support would be found within a clinical population of teenage girls. Results indicated that AS increased their perceived value and appreciation of the task. These findings are coherent with previous studies that have found autonomy support to facilitate the internalization of external tasks to take place in a positive manner (Deci \& Ryan, 2000).

Autonomy support was also found to decrease uncomfortable emotions such as potential anxiety or frustration during a monotonous activity. Such results are coherent with Black and Deci's study (2000) who found that autonomy support decreases anxiety in a learning situation. It is noteworthy that the NoAS context was not associated with especially high negative affect nor especially low positive affect (both being mid-point; Table 3), suggesting that this interpersonal style was neutral, and did not induce unpleasant feelings. This is probably related to the fact that the instructor's enthusiasm and irritability were very similar across conditions.

Regarding positive affect, the difference between groups was not significant. This result is possibly related to the experimental task, chosen for its tedious nature. It is unsurprising that participants did not endorse a high level of positive affect, especially considering that the positive words listed in the scale were not only in the positive valence, but high in activation/arousal (e.g., joyful, enthusiastic; Watson, Wiese, Vaidya, \& Tellegen, 1999). Perhaps positive deactivation words (e.g., contentment) would have better reflected the impact of autonomy support on girls' affective experience.

One goal was to see the impact autonomy support would have on the way teenage girls would see not only the targeted task, but the adult introducing it. In a previous study with college 
students (Boggiano et al., 1993), results suggested that providing choices (one element of AS) led instructors to be judged as less competent. To the contrary, within our sample of teenage girls with severe emotional and behavioral difficulties, participants in the AS condition perceived the new instructor as more competent than participants who interacted with the same instructor, but not using AS. These inconsistent findings may result from differences in manipulation and population. In the study with college students, only the element of choice was manipulated, and students may have perceived this as being a less serious or unexpected attitude for a teacher. In contrast, an autonomy-supportive interpersonal style was manipulated in the present study and perhaps that for youngsters in SRCs, who are used to interact with social rehabilitation professionals, the use of empathy, rationale, choice, and non-controlling language were seen as a strength. Interestingly, the length of received social services also influenced the perceived instructor's competence, but negatively. It is encouraging to see that autonomy support might not only be appealing to maladjusted teenagers, but also promote their positive attitude toward new socializing agents, even when taking into account their tendency to see instructors as less competent, the more they spent time in SRCs.

We aimed to measure the degree to which participants felt that their need for autonomy was satisfied because basic need satisfaction is hypothesised to be the mechanism by which an AS context fosters positive outcomes (Deci \& Ryan, 2000). Though participants in the AS condition reported higher autonomy than girls in NoAS condition, the difference was not statistically significant. Perhaps the lack of significant effect is due to our measure of perceived autonomy. It is possible that "feeling autonomous" is a subtle subjective experience that is difficult to grasp, perhaps particularly among youth with severe emotional problems. Similarly to sophisticated emotion words that are rarely used, the concept of "feeling free" may be a new and 
relatively more difficult concept to notice, identify and monitor. Alternatively, perhaps autonomy is not the primary mechanism driving the manipulation's effect. Though the intervention aimed to increase autonomy, participants may have "felt better" without attributing it readily to their sense of volition. In a recent study (Edmunds et al., 2008), an experimental manipulation of instructors' autonomy-support (vs. neutral) led to positive motivational outcomes, but without significant changes in need satisfaction.

What is it that makes teenagers in the AS condition see the task value and to like it better? In the present study, the two other significant effects of the AS manipulation were on the instructor's perceived competence and on participants' negative affect. Perhaps AS fostered task appreciation and the internalization of its value by diminishing the unpleasant emotions youths in SRC may feel and/or by fostering trust in the instructor. Future research allowing testing mediation links is needed to shed light on the mechanisms involved.

Together, these findings demonstrate that an autonomy-supportive interpersonal style has a positive effect on the internalization of tedious but important tasks, even for more difficult youths who might be nonetheless “pulling” for more controlling strategies (Grolnick, 2003; Grolnick \& Apostoleris, 2002). These findings contradict the popular belief and the usual tendency to introduce external contingencies to prompt tasks that are believed not to be appealing enough to trigger motivation (Reeve et al., 2002).

Conducted with a clinical population, the present study makes an original contribution to the motivation literature. However, it was not without limits. First, due to the recruitment challenges associated with a clinical and young population (e.g., obtaining parental consent, availability of participants), the sample size was small and satisfactory statistical power could not 
be obtained. The small sample size also prevented us from testing potential interaction effects. It would be an interesting future avenue to investigate how an autonomy-supportive manipulation interacts with individual factors (e.g., type of impairment, gender) or interpersonal variables (e.g., educator's style). In a study conducted with two samples of youngsters with different impairments, Deci, Hodges, Pierson, and Tomassone (1992) found that within emotionally handicapped students, it was autonomy (both personal and contextual) that produced the most variance on school achievement and adjustment, whereas it was competence that mattered the most for learning disabled students. At the interpersonal level, educators' habitual interpersonal style may also influence how teenagers react to an autonomy-supportive style.

Second, though conducting a clinical workshop is ecologically valid, the group format may have created score dependency (the experience of participants was not totally independent of the experience of others). To take this aspect into consideration, HLM analyses were conducted to explore whether similar results would be obtained, despite the small size of the sample. A similar pattern of results emerged, suggesting that the initially reported findings were not spurious and reflect the experimental condition's impact. Nevertheless, the present findings should be replicated using a larger sample and HLM analyses.

The studied sample was relatively homogenous (teenage girls experiencing impairments severe enough to be placed in SRCs). The population investigated did not include boys because SRCs are gender specific. This entails that the results of this study cannot be generalized to a clinical sample of teenage boys. Further work should include both genders and adapt the experimental procedure (e.g., same-sex instructor, interest level of the problem-solving task). In addition, in the present experiment, the instructor was a stranger with an unestablished alliance 
with participating teenagers. Whether an autonomy-supportive style would have a similar impact within pre-existing relationships (e.g., with SRCs educators) remains unknown.

Regarding measurement, one limitation is the absence of a measure of perceived autonomy support from the instructor, such as the Learning Climate Questionnaire (Williams \& Deci, 1996). Such a measure could have served as a manipulation check, examining what interpersonal style participants actually perceived, and confirming that girls in the AS condition perceived more autonomy-supportive behaviors from the instructor (e.g., more empathy, rationales) than participants in the NoAS condition. The lack of behavioral measures is a related limitation. Indeed, the present study did not observe participants' engagement and test performance in social problem solving skills. It would have been interesting to examine whether the motivational and well-being benefits were accompanied by learning benefits. Future studies could use a behavioral measure of engagement and assess the quality of participants' work, by having blind coders assess participants' workbooks for example. In addition, though the instructor's level of enthusiasm and irritability was rated, the coder was not blind to the experimental condition.

It would be interesting to explore what interpersonal style educators actually use during the daily life activities and workshops with youths in SRCs, given that the relationship adolescents have with them may have a pervasive impact on their motivation and social rehabilitation. Future studies could also assess educators' subjective experience to shed light on the processes involved in the social rehabilitation context. For example, potential determinants of autonomy support could be explored . Indeed, Grolnick and Apostoleris (2002) identify the level of child "difficulty" or "pressure from below" as influencing the degree to which socializing 
agents support children's autonomy, in addition to "pressure from within” (e.g., educators' perfectionism) and "pressure from without" (e.g., high demands from a superior).

Before trying to teach socializing agents to be autonomy-supportive, we believe it would be important to explore how they can be supported themselves in using this approach with an especially difficult population that is recognized as to "pull for control" (Grolnick, 2003).

Thereafter, experimental studies could explore in vivo the impact of teaching AS strategies to educators on youth internalization and social rehabilitation.

As it has been theoretically and empirically supported in other contexts and within the general population, autonomy support seems to be protective and support a healthy motivational development of teenage girls placed in SRCs. Notwithstanding that self-determination and its putative benefits do not represent a sufficient condition in preventing the recurrence of youths' problems, this study suggests that AS can facilitate internalization and sustain the development of social adjustment. Indeed, the present results extend previous findings by demonstrating that not only autonomy-support promotes self-determined motivation and healthy internalization, it can also improve the subjective experience during a tedious task and do so within a clinical population of severely maladjusted teenage girls. This study suggests that not only regular, welldeveloped and well-functioning youngsters benefit from autonomy support. The fact that more difficult youths "pull for control" does not imply that they need more controlling tactics. This study contradicts the prevalent belief that difficult children and adolescents need more extrinsic motivators.

By extending the benefits of autonomy support to especially difficult teenage girls who require to be placed in SRCs to be rehabilitated, this study supports the universality proposed by SDT. It seems that the natural tendency to grow healthy can be supported by autonomy- 
supportive social contexts, regardless of youths' vulnerabilities and general tendencies (see Ryan et al., 2006, p. 840). If our society is oriented toward long-term social rehabilitation rather than mere coercive restrictions of social misconducts, autonomy-supportive contexts that promote a healthy development should be provided to youths in social rehabilitation. Social and educational policies should be oriented as to support and promote the learning and the integration of an autonomy-supportive interpersonal style within educational and clinical settings, such as youth social rehabilitation centers. 


\section{References}

Anderson, K. E., Lytton, H., \& Romney, D. M. (1986). Mothers' interactions with normal and conduct-disordered boys: Who affects whom? Developmental Psychology, 22(5), 604609. doi: 10.1037/0012-1649.22.5.604

Barber, B. K. (1996). Parental psychological control: Revisiting a neglected construct. Child Development, 67(6), 3296-3319. doi: http://dx.doi.org/10.2307/1131780

Black, A. E., \& Deci, E. L. (2000). The effects of instructors' autonomy support and students' autonomous motivation on learning organic chemistry: A self-determination theory perspective. Science Education, 84(6), 740-756.

Blais, M. R., \& Vallerand, R. J. (1991). Échelle de perception d'autodétermination dans les domaines de vie (ÉPADV-16). Université du Québec à Montréal. Montréal.

Boggiano, A. K., Flink, C., Shields, A., Seelbach, A., \& Barrett, M. (1993). Use of techniques promoting students' self-determination: Effects on students' analytic problem-solving skills. Motivation and Emotion, 17(4), 319-336. doi: 10.1007/bf00992323

Centre Jeunesse de Montréal, I.-U. (2011). Rapport annuel 2010-2011. Montréal: Centre Jeunesse de Montréal.

Connell, J. P., \& Wellborn, J. G. (1991). Competence, autonomy, and relatedness: A motivational analysis of self-system processes. In M. R. Gunnar \& L. A. Sroufe (Eds.), Self processes and development. (pp. 43-77): Hillsdale, NJ, England: Lawrence Erlbaum Associates, Inc.

Conners, K. C. (2000). Conners' Rating Scales-Revised Technical Manual. North Tonawanda, New York: Multi Health Systems. 
De Charms, R. (1968). Personal causation: The internal affective determinants of behaviour. New York, NY: Academic Press.

Deci, E. L., Eghrari, H., Patrick, B. C., \& Leone, D. R. (1994). Facilitating internalization: The self-determination theory perspective. Journal of Personality, 62(1), 119-142.

Deci, E. L., Hodges, R., Pierson, L. H., \& Tomassone, J. (1992). Autonomy and competence as motivational factors in students with learning disabilities and emotional handicaps. Journal of Learning Disabilities, 25(7), 457-471. doi: http://dx.doi.org/10.1177/002221949202500706

Deci, E. L., \& Ryan, R. M. (1980). The Empirical Exploration of Intrinsic Motivational Processes. In B. Leonard (Ed.), Advances in Experimental Social Psychology (Vol. Volume 13, pp. 39-80): Academic Press.

Deci, E. L., \& Ryan, R. M. (1985). Intrinsic Motivation and Self-Determination in Human Behaviour. New York, NY: Plenum Press.

Deci, E. L., \& Ryan, R. M. (1991). A motivational approach to self: Integration in personality. In R. Dienstbier (Ed.), Perspectives on Motivation. Lincoln, Neb: University of Nebraska Press.

Deci, E. L., \& Ryan, R. M. (2000). The "what" and "why" of goal pursuits: Human needs and the self-determination of behavior. Psychological Inquiry, 11(4), 227-268. doi: http://dx.doi.org/10.1207/S15327965PLI1104_01

Deci, E. L., \& Ryan, R. M. (2002). The paradox of achievement: The harder you push, the worse it gets'. In J. Aronson (Ed.), Improving Academic Achievement: Contributions of Social Psychology (pp. 59-85). New York: Academic Press. 
Edmunds, J., Ntoumanis, N., \& Duda, J. L. (2008). Testing a self-determination theory-based teaching style intervention in the exercise domain. European Journal of Social Psychology, 38(2), 375-388. doi: 10.1002/ejsp.463

Faber, A., \& Mazlish, E. (1980). How to Talk so Kids will Listen and Listen so Kids will Talk. New York, NY: Rawson, Wade Publishers.

Forest, J., \& Mageau, G. (2008). Intrinsic need satisfaction as a mediator between harmonious passion and psychological adjustment at work. Manuscript in preparation, Université du Québec à Montréal school of management sciences.

Ginott, H. G. (1959). The theory and practice of "therapeutic intervention" in child treatment. Journal of Consulting Psychology, 23, 160-166.

Ginott, H. G. (1965). Between parent and child. New York: Macmillan.

Grolnick, W. S. (2003). The psychology of parental control: How well-meant parenting backfires. Mahwah, NJ: Lawrence Erlbaum Associates Publishers; US.

Grolnick, W. S., \& Apostoleris, N. H. (2002). What makes parents controlling? [References] Handbook of self-determination research (pp. 161-181). Rochester, NY: University of Rochester Press; US.

Grusec, J. E., Goodnow, J. J., \& Kuczynski, L. (2000). New Directions in Analyses of Parenting Contributions to Children's Acquisition of Values. Child Development, 71(1), 205-211. doi: $10.1111 / 1467-8624.00135$

Grusec, J. E., \& Kuczynski, L. (1997). A history of research on parenting strategies and children's internalization of values. In G. a. L. Kuczynski (Ed.), Parenting and children's internalization of values: A handbook of contemporary theory (pp. xxiv, 439). Hoboken, NJ: John Wiley \& Sons Inc; US. 
Hardre, P. L., \& Reeve, J. (2003). A motivational model of rural students' intentions to persist in, versus drop out of, high school. Journal of Educational Psychology, 95(2), 347-356. doi: http://dx.doi.org/10.1037/0022-0663.95.2.347

Jang, H. (2008). Supporting students' motivation, engagement, and learning during an uninteresting activity. Journal of Educational Psychology, 100(4), 798-811. doi: $10.1037 / \mathrm{a} 0012841$

Jang, H., Reeve, J., \& Deci, E. L. (2010). Engaging students in learning activities: It is not autonomy support or structure but autonomy support and structure. Journal of Educational Psychology, 102(3), 588-600. doi: http://dx.doi.org/10.1037/a0019682

Jelsma, B. M. (1982). Adult control behaviors: The interaction between orientation toward control in women and activity level in children. [Dissertation]. Dissertation Abstracts International, 43(6-A), 1892-1893.

Joussemet, M., Koestner, R., Lekes, N., \& Houlfort, N. (2004). Introducing uninteresting tasks to children: A comparison of the effects of rewards and autonomy support. Journal of Personality, 72(1), 139-166. doi: http://dx.doi.org/10.1111/j.0022-3506.2004.00259.x

Koestner, R., Ryan, R. M., Bernieri, F., \& Holt, K. (1984). Setting limits on children's behavior: The differential effects of controlling vs. informational styles on intrinsic motivation and creativity. Journal of Personality, 52(3), 233-248. doi: http://dx.doi.org/10.1111/j.14676494.1984.tb00879.x

La Guardia, J. G., \& Ryan, R. M. (2002). What adolescents need: A self-determination theory perspective on development within families, school, and society. In F. Pajares \& T. Urdan (Eds.), Academic Motivation of Adolescents (pp. 193-220). Greenwich: Information Age Publishing, Inc. 
La Guardia, J. G., Ryan, R. M., Couchman, C. E., \& Deci, E. L. (2000). Within-person variation in security of attachment: A self-determination theory perspective on attachment, need fulfillment, and well-being. Journal of Personality and Social Psychology, 79(3), 367384. doi: http://dx.doi.org/10.1037/0022-3514.79.3.367

Lanctôt, N. (2006). Les adolescentes prises en charge par le Centre Jeunesse : Que deviennentelles au tournant de la vingtaine? Défi Jeunesse, XII(2), 3-8.

Laurent, J., Catanzaro, S. J., Joiner, T. E., Jr., Rudolph, K. D., Potter, K. I., Lambert, S., . . Gathright, T. (1999). A measure of positive and negative affect for children: Scale development and preliminary validation. Psychological Assessment, 11(3), 326-338. doi: http://dx.doi.org/10.1037/1040-3590.11.3.326

Nie, Y., \& Lau, S. (2009). Complementary roles of care and behavioral control in classroom management: The self-determination theory perspective. Contemporary Educational Psychology, 34(3), 185-194. doi: http://dx.doi.org/10.1016/j.cedpsych.2009.03.001

Raudenbusch, S., \& Bryk, A. (2002). Hierarchical Linear Models applications and data analysis methods. Thousand Oaks, CA: Sage.

Reeve, J. (2009). Why teachers adopt a controlling motivating style toward students and how they can become more autonomy supportive. Educational Psychologist, 44(3), 159-175. doi: http://dx.doi.org/10.1080/00461520903028990

Reeve, J., Jang, H., Carrell, D., Jeon, S., \& Barch, J. (2004). Enhancing Students' Engagement by Increasing Teachers' Autonomy Support. Motivation and Emotion, 28(2), 147-169. doi: http://dx.doi.org/10.1023/B:MOEM.0000032312.95499.6f 
Reeve, J., Jang, H., Hardre, P., \& Omura, M. (2002). Providing a Rationale in an AutonomySupportive Way as a Strategy to Motivate Others During an Uninteresting Activity. Motivation and Emotion, 26(3), 183-207. doi: 10.1023/a:1021711629417

Ryan, R. M. (1982). Control and information in the intrapersonal sphere: An extension of cognitive evaluation theory. Journal of Personality and Social Psychology, 43(3), 450461. doi: http://dx.doi.org/10.1037/0022-3514.43.3.450

Ryan, R. M. (1995). Psychological needs and the facilitation of integrative processes. Journal of Personality, 63(3), 397-427. doi: http://dx.doi.org/10.1111/j.1467-6494.1995.tb00501.x

Ryan, R. M., \& Deci, E. L. (2000). Self-determination theory and the facilitation of intrinsic motivation, social development, and well-being. American Psychologist, 55(1), 68-78. doi: http://dx.doi.org/10.1037/0003-066X.55.1.68

Ryan, R. M., Deci, E. L., Grolnick, W. S., \& La Guardia, J. G. (2006). The significance of autonomy and autonomy support in psychological development and psychopathology Developmental psychopathology, Vol 1: Theory and method (2nd ed., pp. 795-849). Hoboken, NJ: John Wiley \& Sons Inc; US.

Schultz, L. H., Selman, R. L., \& Yeates, K. O. (1989). The interpersonal negotiation strategies interview manual. Harvard University Cambridge, MA.

Sheldon, K. M., \& Filak, V. (2008). Manipulating autonomy, competence, and relatedness support in a game-learning context: New evidence that all three needs matter. British Journal of Social Psychology, 47(2), 267-283. doi: http://dx.doi.org/10.1348/014466607X238797

Sierens, E., Vansteenkiste, M., Goossens, L., Soenens, B., \& Dochy, F. (2009). The synergistic relationship of perceived autonomy support and structure in the prediction of self- 
regulated learning. British Journal of Educational Psychology, 79(1), 57-68. doi: $10.1348 / 000709908 \times 304398$

Soenens, B. (2006). Psychologically controlling parenting and adolescent psychosocial adjustment: antecedents, mediating factors, and longitudinal dynamics. (Ph.D), Universiteit Ghent, Centre for Developmental Psychology. Retrieved from http://hdl.handle.net/1979/417

Thibault, M. (2005). Portrait des jeunes âgés de 0 à 17 ans référés à la prise en charge des Centres jeunesse du Québec, leur parcours dans les services et leur évolution dans le temps. Groupe de recherche sur les inadaptations sociales de l'enfance (pp. 17). http://www.grise.ca/documents/publications/synthse_complte_fass.pdf: Université de Sherbrooke.

Toupin, J., Pauzé, R., \& Déry, M. (2005). Les services des Centres jeunesse offerts aux adolescents ayant des troubles de comportement I : Association avec les difficultés des jeunes et des familles. Revue de Psychoéducation. Revue de Psychoéducation, 34(2), 1739.

Tsai, Y.-M., Kunter, M., Ludtke, O., Trautwein, U., \& Ryan, R. M. (2008). What makes lessons interesting? The role of situational and individual factors in three school subjects. Journal of Educational Psychology, 100(2), 460-472. doi: http://dx.doi.org/10.1037/00220663.100 .2 .460

Vallerand, R. J., \& Bissonnette, R. (1992). Intrinsic, extrinsic, and amotivational styles as predictors of behavior: A prospective study. Journal of Personality, 60(3), 599-620. doi: http://dx.doi.org/10.1111/j.1467-6494.1992.tb00922.x 
Vallerand, R. J., Fortier, M. S., \& Guay, F. (1997). Self-determination and persistence in a reallife setting: Toward a motivational model of high school dropout. Journal of Personality and Social Psychology 72(5), 1161-1176. doi: http://dx.doi.org/10.1037/00223514.72.5.1161

Vansteenkiste, M., Niemiec, C., \& Soenens, B. (2010). The development of the five minitheories of self-determination theory: An historical overview, emerging trends, and future directions. In U. T. K. S. (Ed.), Advances in Motivation and Achievement (Vol. 16: The decade ahead, pp. 105-166). UK: Emerald Publishing.

Watson, D., Clark, L. A., \& Tellegen, A. (1988). Development and validation of brief measures of positive and negative affect: The PANAS scales. Journal of Personality and Social Psychology, 54(6), 1063-1070. doi: http://dx.doi.org/10.1037/0022-3514.54.6.1063

Watson, D., Wiese, D., Vaidya, J., \& Tellegen, A. (1999). The two general activation systems of affect: Structural findings, evolutionary considerations, and psychobiological evidence. Journal of Personality and Social Psychology, 76(5), 820-838. doi: http://dx.doi.org/10.1037/0022-3514.76.5.820

Williams, G. C., \& Deci, E. L. (1996). Internalization of biopsychosocial values by medical students: A test of self-determination theory. Journal of Personality and Social Psychology, 70(4), 767-779. doi: 10.1037/0022-3514.70.4.767

Witzel, B. S., \& Mercer, C. D. (2003). Using rewards to teach students with disabilities: Implications for motivation. Remedial and Special Education, 24(2), 88-96. doi: http://dx.doi.org/10.1177/07419325030240020401 


\section{Footnotes}

${ }^{1}$ In Quebec (Canada), Youth and Family Centres (YFCs; Centres Jeunesse) provide psychosocial, rehabilitation, and social integration services in relation to The Youth Protection Act (81\%), The Youth Criminal Justice Act (14\%) and An Act respecting Health Services and Social Services (4\%; Centre Jeunesse de Montréal, 2011). These laws and their related services all entail to a same purpose, to allow children and adolescents to live and grow in safe and stable environments by providing services related to child placement, adoption/adoption disclosure, expertise to court and mediation. Quebec has a unique and complex social rehabilitation system which may defer from those encountered in the rest of Canada and the United States. Social Rehabilitation Centers (SRCs) are residential placement settings that cannot be compared to detention centers, foster homes/groups or in-patient mental hospitals because it has goals of protection (individuals and society) and treatment.

${ }^{2}$ Groups were assigned to a workshop time according to availabilities. In order to facilitate the instructor's script fidelity, the schedule was established so that only one interpersonal style (AS or NoAS) would be used within a testing day. The experimental condition of the day was decided by chance for the first day and alternated subsequently.

${ }^{3}$ Despite the presence of orders and evaluative feedback, the NoAS experimental condition is conceptualized here as typical/neutral because this language is considered mainstream and widely used during learning activities. Controlling contexts are not only defined by the use of controlling language, but also by the use of expected rewards, intrusion, pressure, threats and guilt induction (Reeve, 2009). None of those elements were present in the NoAS condition. Therefore, though in this study requests had to be made and limits set, we believe that 
the use of mainstream language without the addition of controlling components makes this condition a "neutral" or "typical" one. 


\section{Appendix}

For informational purpose, items from the scales used to measure the task value, task

liking, feeling of autonomy and affect appear below (items were freely translated from French to English). The French versions can be obtained from the corresponding author.

\section{Task Value:}

The topic was meaningful to me

It was important to me that I thoroughly understand the material covered

I thought that the content of the lesson could be useful in real life

This activity was personally important to me

I consider that doing this activity was worthless to me (Reversed)

\section{Task Liking:}

I appreciated solving dilemmas

I found the activity interesting

I did this activity because it was fun for me

I found the dilemmas interesting

\section{Autonomy:}

During the activity...

I felt free to be myself

I felt like I was in jail (reverse scored)

I felt free to express my ideas and my opinions

I felt suppressed (reverse scored)

I felt I had to do what I was told (reverse scored)

I felt free to do the tasks at my how pace and according to my values 
I felt pressured (reverse scored)

I felt there was space for my ideas

I felt I had choices about how to apply the learned skills

\section{Affect:}

During the activity, I felt...

\section{Positive Affect:}

Happy

Energetic

Good mood

Attentive

Enthusiastic

Negative Affect:

Angry

Impatient

Nervous

Frustrated

Anxious
In a good shape

Alert

Interested

Cheerful

Glad

Sad

Worried

Stressed

Disappointed

Depressed 
AUTONOMY SUPPORT FOR ADOLESCENTS WITH PROBLEMS

Table 1

Experimental Conditions' Comparisons

Autonomy Support (AS)

No Autonomy Support (NoAS)

Interventions

Rational

Empathy

Choice

Feedback

Limit setting

Taking action
"Before starting girls, I would like to tell you the reason why we practice together with a fictive story today. It's because it might be easier to solve an imaginary problem than a real life problem, like a fight for example. [...] So, first we practice with fake problems and then, the more we practice, the more it might become natural and easier to do. After that, when you will be facing a real fight that you want to solve, this is likely to help you!"

"Even then, it is not necessarily easy to solve a fictive problem, because it is new and it might seem like a lot of steps to learn!"

"It might be very difficult to remain silent when sitting beside a friend"

"This answer sheet contains the same questions (steps) as in the first vignette; you can do it in the order that is the most helpful to you".

Descriptive: "I see you have found 3 solutions!"

"I'm expecting that..." "This part requires to be done in silence".

"It might be very difficult to be silent when sitting beside a friend ..."; " if it is too difficult, you can choose to sit elsewhere"; "I see you chose to sit elsewhere".
None

None

None

Evaluative: "Amazing! You are really good at this!"

"What you have to do is..." "Please be quiet".

"Stop talking"; "if you don't stop, you will have to sit elsewhere"; "Go sit there". 


\section{AUTONOMY SUPPORT FOR ADOLESCENTS WITH PROBLEMS}

Table 2

Means and Standard Deviations by Experimental Conditions

\begin{tabular}{|c|c|c|c|c|}
\hline \multirow[b]{2}{*}{ Measures } & \multicolumn{2}{|c|}{$\begin{array}{l}\text { Autonomy Support } \\
\qquad(\mathrm{AS} ; n=17)\end{array}$} & \multicolumn{2}{|c|}{$\begin{array}{l}\text { No Autonomy Support } \\
\qquad(\text { NoAS; } n=12)\end{array}$} \\
\hline & $M$ & $S D$ & $M$ & $S D$ \\
\hline $\begin{array}{l}\text { Autonomy- } \\
\text { supportive } \\
\text { comments }\end{array}$ & 7.12 & 1.97 & 1.50 & 0.91 \\
\hline $\begin{array}{l}\text { Typical } \\
\text { comments }\end{array}$ & 0.35 & 0.79 & 4.42 & 0.52 \\
\hline $\begin{array}{l}\text { Instructor's } \\
\text { enthusiasm }\end{array}$ & 5.00 & 0.61 & 4.75 & 0.45 \\
\hline $\begin{array}{l}\text { Instructor's } \\
\text { irritability }\end{array}$ & 1.35 & 0.39 & 1.17 & 0.49 \\
\hline Positive affect & 4.54 & 1.61 & 3.64 & 1.71 \\
\hline Negative affect & 1.82 & 0.84 & 3.37 & 1.71 \\
\hline Autonomy & $5.34 / 5.27^{\mathrm{a}}$ & 1.21 & $4.81 / 4.97^{\mathrm{a}}$ & 1.44 \\
\hline Task value & $5.05 / 4.98^{\mathrm{a}}$ & 1.46 & $3.40 / 3.45^{\mathrm{a}}$ & 1.36 \\
\hline Task liking & 4.79 & 1.65 & 3.19 & 1.77 \\
\hline $\begin{array}{l}\text { Perceived } \\
\text { instructor's } \\
\text { competence }\end{array}$ & $5.59 / 5.44^{b}$ & 1.16 & $3.71 / 3.93^{b}$ & 2.21 \\
\hline
\end{tabular}

Note. Means with superscripts are adjusted means for (a) baseline autonomy and (b) for length of stay at the SRC. 


\section{AUTONOMY SUPPORT FOR ADOLESCENTS WITH PROBLEMS}

Table 3

Pearson Correlations Among Dependent Variables

\begin{tabular}{|c|c|c|c|c|c|}
\hline Measures & 2. & 3. & 4. & 5. & 6. \\
\hline 1. Positive affect & $-.41 *$ & $.68 * *$ & $.69 * *$ & $.81 * *$ & $.72 * *$ \\
\hline \multicolumn{2}{|l|}{ 2. Negative affect } & $-.54 * *$ & $-.46 *$ & $-.45 *$ & $-.55 * *$ \\
\hline \multicolumn{2}{|l|}{ 3. Autonomy } & & $.66 * *$ & $.78 * *$ & $.73 * *$ \\
\hline \multicolumn{2}{|l|}{ 4. Task value } & & & $.90 * *$ & $.72 * *$ \\
\hline \multicolumn{2}{|l|}{ 5. Task liking } & & & & $.82 * *$ \\
\hline \multicolumn{2}{|c|}{$\begin{array}{l}\text { 6. Perceived instructor's } \\
\text { competence }\end{array}$} & & & & \\
\hline
\end{tabular}

Note. ${ }^{*} p<.05$. $* * p<.01$. 